\title{
Patients with COVID-19 in 19 ICUs in Wuhan, China: a cross-sectional study
}

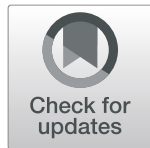

Yuan $\mathrm{Yu}^{1 \dagger}$, Dan $\mathrm{Xu}^{1 \dagger}$, Shouzhi $\mathrm{Fu}^{2+}$, Jun Zhang ${ }^{3+}$, Xiaobo Yang ${ }^{1 \dagger}$, Liang $\mathrm{Xu}^{4 \dagger}$, Jiqian $\mathrm{Xu}^{1}$, Yongran $\mathrm{Wu}^{1}$, Chaolin Huang ${ }^{5}$, Yaqi Ouyang ${ }^{1}$, Luyu Yang ${ }^{2}$, Minghao Fang ${ }^{6}$, Hongwen Xiao ${ }^{7}$, Jing Ma ${ }^{8}$, Wei Zhu ${ }^{9}$, Song Hu ${ }^{10}$, Quan $\mathrm{Hu}^{11}$, Daoyin Ding ${ }^{11}$, Ming Hu${ }^{12}$, Guochao Zhu ${ }^{13}$, Weijiang Xu ${ }^{14}$, Jun Guo ${ }^{15}$, Jinglong Xu ${ }^{15}$, Haitao Yuan ${ }^{16}$, Bin Zhang ${ }^{17}$, Zhui $\mathrm{Yu}^{18^{*}}$, Dechang Chen ${ }^{19^{*}}$, Shiying Yuan ${ }^{1 *}$ and You Shang ${ }^{1 *}$

\begin{abstract}
Background: A COVID-19 outbreak started in Wuhan, China, last December and now has become a global pandemic. The clinical information in caring of critically ill patients with COVID-19 needs to be shared timely, especially under the situations that there is still a largely ongoing spread of COVID-19 in many countries.
\end{abstract}

Methods: A multicenter prospective observational study investigated all the COVID-19 patients received in 19 ICUs of 16 hospitals in Wuhan, China, over $24 \mathrm{~h}$ between 8 AM February $2 \mathrm{~h}$ and 8 AM February 27, 2020. The demographic information, clinical characteristics, vital signs, complications, laboratory values, and clinical managements of the patients were studied.

Results: A total of 226 patients were included. Their median (interquartile range, IQR) age was 64 (57-70) years, and 139 (61.5\%) patients were male. The duration from the date of ICU admission to the study date was 11 (5-17) days, and the duration from onset of symptoms to the study date was 31 (24-36) days. Among all the patients, 155 (68.6\%) had at least one coexisting disease, and their sequential organ failure assessment score was 4 (2-8). Organ function damages were found in most of the patients: ARDS in 161 (71.2\%) patients, septic shock in 34 (15.0\%) patients, acute kidney injury occurred in 57 (25.2\%) patients, cardiac injury in 61 (27.0\%) patients, and lymphocytopenia in 160 (70.8\%) patients. Of all the studied patients, 85 (37.6\%) received invasive mechanical ventilation, including 14 (6.2\%) treated with extracorporeal membrane oxygenation (ECMO) at the same time, 20 (8.8\%) received noninvasive mechanical ventilation, and $24(10.6 \%)$ received continuous renal replacement therapy. By April 9, 2020, 87 (38.5\%) patients were deceased and 15 (6.7\%) were still in the hospital.

(Continued on next page)

\footnotetext{
*Correspondence: yuzhui@whu.edu.cn; icudechangchen@163.com; yuan_shiying@163.com; you_shanghust@163.com

†Yuan Yu, Dan Xu, Shouzhi Fu, Jun Zhang, Xiaobo Yang and Liang Xu contributed equally to this work.

${ }^{18}$ Department of Critical Care Medicine, Renmin Hospital of Wuhan University, Wuhan, China

${ }^{19}$ Department of Critical Care Medicine, Ruijin Hospital, Shanghai Jiao Tong University School of Medicine, Shanghai, China

${ }^{1}$ Department of Critical Care Medicine, Union Hospital, Tongji Medical College, Huazhong University of Science and Technology, Wuhan, China Full list of author information is available at the end of the article
}

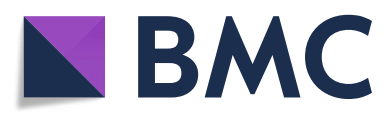

(c) The Author(s). 2020 Open Access This article is licensed under a Creative Commons Attribution 4.0 International License which permits use, sharing, adaptation, distribution and reproduction in any medium or format, as long as you give appropriate credit to the original author(s) and the source, provide a link to the Creative Commons licence, and indicate if changes were made. The images or other third party material in this article are included in the article's Creative Commons licence, unless indicated otherwise in a credit line to the material. If material is not included in the article's Creative Commons licence and your intended use is not permitted by statutory regulation or exceeds the permitted use, you will need to obtain permission directly from the copyright holder. To view a copy of this licence, visit http://creativecommons.org/licenses/by/4.0/. The Creative Commons Public Domain Dedication waiver (http://creativecommons.org/publicdomain/zero/1.0/) applies to the data made available in this article, unless otherwise stated in a credit line to the data. 
(Continued from previous page)

Conclusions: Critically ill patients with COVID-19 are associated with a higher risk of severe complications and need to receive an intensive level of treatments. COVID-19 poses a great strain on critical care resources in hospitals.

Trial registration: Chinese Clinical Trial Registry, ChiCTR2000030164. Registered on February 24, 2020, http://www. chictr.org.cn/edit.aspx?pid=49983\&htm=4

Keywords: COVID-19, Critically ill patients, Complications, Epidemic

\section{Background}

In December 2019, a series of patients in Wuhan, China, showed pneumonia-related symptoms and later being diagnosed as a novel coronavirus-caused infectious disease (COVID-19) that marks the outbreak of the epidemic [1-3]. The spread of the virus is an emerging, rapidly evolving situation and had been declared as a global pandemic by the WHO since March 11, 2020. As of March 15, 2020, there were 153,517 cases being identified worldwide [4], with 50, 003 cases from Wuhan [5]. The COVID-19 pandemic poses enormous burdens and challenges to the medical care system, including intensive care units (ICUs), across different countries [6]. The higher mortality of critically ill patients was reported to be associated with the severity of the shortage of healthcare resources [7].

Previously published studies in describing the epidemiological findings, clinical presentation, and clinical outcomes of the COVID-19 patients were mainly on non-critical patients [8-10]. To our knowledge, there is only one study that was conducted with critical patients at an early time of the epidemic, which was further limited in the small sample size for the analysis [11]. In addition, all those abovementioned were retrospective studies that may be associated with possible biases or misclassifications due to the nature of retrospective looking. We conducted a multicenter 1-day crosssectional study on critically ill patients with COVID-19 in 19 local ICUs in Wuhan. Our objective was to elaborate on the outcomes and complications of patients with COVID-19 and the intensity of treatments these patients had received.

\section{Methods}

\section{Study design}

This cross-sectional study was a multicenter, prospective, observational study, in which the study subjects are the patients who were received over 1 day, from 8 AM February 26, 2020, to 8 AM the next day. The involved 19 ICUs are from 16 hospitals that are designated solely for treating COVID-19 patients in Wuhan since the outbreak. There were two coordinative physicians from each of the ICU site joining the study team, who had at least a 3-year ICU working experience. All the ICUs have met the following criteria: having closed adult units, at least 10 beds, and staffed by full-time intensive care physicians and nurses covering $24 \mathrm{~h}$ for 7 days. Using a web-based case report form (CRF), after two rounds of pilot testing and modification, each ICU was able to perform a password-protected login to the CRF through a mobile phone connection.

All the patients in these ICUs, who were diagnosed with COVID-19 according to the Fifth Edition of Diagnosis and Treatment Protocols for Patients with Novel Coronavirus Pneumonia released by the $\mathrm{Na}$ tional Health Commission of China, were registered into the study. No formal exclusion criteria were planned, and all patients' identifiable information had been de-identified before being stored and analyzed. The study was registered in the Chinese Clinical Trial Registry (ChiCTR2000030164).

\section{The criteria for ICU admission}

Patients were admitted to the ICUs if they met one of the following criteria: a respiratory rate of more than 40 breaths per minute, a pressure of arterial oxygen less than $60 \mathrm{mmHg}$ or pulse oxygen saturation less than $90 \%$ while the patient was breathing oxygen at a flow rate of $7 \mathrm{~L}$ per minute or more for at least $30 \mathrm{~min}$, a pressure of arterial carbon dioxide higher than $50 \mathrm{mmHg}$, hemodynamic instability and use of vasopressors, a Glasgow Coma Scale score of 12 points or lower, and need of continuous renal replacement therapy (CRRT).

\section{Data collection and definitions}

The coordinative physicians at each site were responsible for collecting the following data from the study patients: (1) demographic information, including gender, age, pregnancy yes/no if female, occupation, date of onset of symptoms, and date of admission to ICU; (2) comorbidities; (3) vital signs and complications; (4) results of laboratory test on the study date; (5) major treatments; and (6) outcomes. The living status of all patients was followed up by April 9, 2020. If there were questions or uncertainties in the collection, the physicians went to talk to the patients' primary care doctors for the answer or the best judgment. 
In the study, acute respiratory distress syndrome (ARDS) was defined according to the Berlin definition [12], septic shock was defined according to the Sepsis-3 criteria [13], and acute kidney injury (AKI) was defined according to the KDIGO criteria [14]. Cardiac injury was defined as the hs-TnI $>28 \mathrm{ng} / \mathrm{L}$ or $\mathrm{TnI}>0.3 \mathrm{ng} / \mathrm{mL}$.

\section{Family information and visitation policies}

The National Health Commission of China released a statement to classify COVID-19 as a category B infectious disease under the law on prevention and control of infectious diseases but take preventive and control measures of category A infectious diseases. COVID-19 was put under quarantinable infectious disease management according to the Frontier Health and Quarantine Law. Wuhan city was locked down on January 23, 2020; citizens included the family of COVID-19 patients who were asked to stay at home and not go out if not necessary. All the hospitalization patients are not allowed to be visited.

\section{Statistical analysis}

We expressed descriptive data as median (with interquartile range) for continuous variables and count (\%) for categorical variables. All analyses were carried out using the Stata/IC 15.1 software (StataCorp, College Station, TX, USA).

\section{Results}

\section{Demographic and clinical characteristics}

Data were collected from 226 patients. The number of xpatients included per ICU was 9 (7-19). Of all the patients, 217 (96.0\%) were admitted to ICUs before $8 \mathrm{AM}$ on February 26, 2020, and the remaining 9 (4.0\%) patients were admitted to ICUs during the study period. Their age was 64 (57-70) years; 139 (61.5\%) patients were male, and $22(9.7 \%)$ patients were medical workers (Table 1). No female patients were during pregnancy. The duration from the time of ICU admission to the study date was 11 (5-17) days, and the duration from the onset of symptoms to the study date was 31 (24-36) days. Among all the patients, $155(68.6 \%)$ had at least one coexisting disease. The common comorbidities were hypertension $96(42.5 \%)$, diabetes $47(20.8 \%)$, coronary heart disease $22(9.7 \%)$, cerebrovascular disease $15(6.6 \%)$, and chronic pulmonary disease 15 (6.6\%). Twelve (5.3\%) patients refused endotracheal intubation, and 11 (4.9\%) patients declared do-not-resuscitate.

\section{Vital signs, complications, and laboratory tests}

The vital signs in Table 2 show nothing notable, but there were patients with dysrhythmia, including 18
Table 1 Demographics, clinical characteristics, and clinical outcomes of 226 patients with Coivd-19 in ICUs

\begin{tabular}{|c|c|}
\hline Characteristics & $\begin{array}{l}\text { All patients } \\
(n=226)\end{array}$ \\
\hline Age, years & $64(57-70)$ \\
\hline \multicolumn{2}{|l|}{ Gender } \\
\hline Male & $139(61.5 \%)$ \\
\hline Female & $87(38.5 \%)$ \\
\hline \multicolumn{2}{|l|}{ Occupation } \\
\hline Medical worker & $22(9.7 \%)$ \\
\hline Unprotected exposure history & $22(100 \%)$ \\
\hline Non-medical worker & $204(90.3 \%)$ \\
\hline Newly admitted to ICU & $9(4.0 \%)$ \\
\hline $\begin{array}{l}\text { Duration from the onset of symptom to the current } \\
\text { study, days }\end{array}$ & $31(24-36)$ \\
\hline Duration from ICU admission to the current study, days & $11(5-17)$ \\
\hline Comorbidities & $155(68.6 \%)$ \\
\hline Hypertension & $96(42.5 \%)$ \\
\hline Coronary heart disease & $22(9.7 \%)$ \\
\hline Myocardial infarction & $6(2.7 \%)$ \\
\hline Congestive heart failure & $4(1.8 \%)$ \\
\hline Diabetes & $47(20.8 \%)$ \\
\hline Diabetes with organ damage & $10(4.4 \%)$ \\
\hline Diabetes without organ damage & $37(16.4 \%)$ \\
\hline Cerebrovascular disease & $15(6.6 \%)$ \\
\hline Chronic pulmonary disease & $15(6.6 \%)$ \\
\hline Chronic hepatopathy & $3(1.3 \%)$ \\
\hline Chronic nephrosis (without regular dialysis) & $3(1.3 \%)$ \\
\hline Chronic nephrosis (with regular dialysis) & $5(2.2 \%)$ \\
\hline Chronic peptic ulcer & $4(1.8 \%)$ \\
\hline Connective tissue disease & $1(0.4 \%)$ \\
\hline Hemiplegia & $4(1.8 \%)$ \\
\hline Alzheimer's disease & $4(1.8 \%)$ \\
\hline Leukemia or lymphoma & $1(0.4 \%)$ \\
\hline Malignancy tumor & $10(4.4 \%)$ \\
\hline $\begin{array}{l}\text { Receive radiotherapy, chemotherapy, and long-term } \\
\text { or high-dose corticoid therapy }\end{array}$ & $1(0.4 \%)$ \\
\hline Refusal of endotracheal intubation & $12(5.3 \%)$ \\
\hline Declaration of do-not-resuscitate & $11(4.9 \%)$ \\
\hline \multicolumn{2}{|l|}{ Clinical outcome } \\
\hline Remained in ICU & $204(90.3 \%)$ \\
\hline Discharged from ICU & $13(5.7 \%)$ \\
\hline Died & $9(4.0 \%)$ \\
\hline
\end{tabular}

Data are expressed as median (interquartile range) or count (\%) COVID-19 coronavirus disease 2019 , ICU intensive care unit

(8.0\%) with atrial fibrillation, 2 (0.9\%) with supraventricular tachycardia, and $1(0.4 \%)$ with ventricular tachycardia. 
Table 2 Vital signs and complications of 226 patients with COVID-19 in ICUs

\begin{tabular}{|c|c|}
\hline Characteristics & $\begin{array}{l}\text { All patients } \\
(n=226)\end{array}$ \\
\hline Heart rate $(\mathrm{bpm})$ & $90(76-103)$ \\
\hline Heart rate $>125$ & $9(4.0 \%)$ \\
\hline Systolic blood pressure (mmHg) & $125(110-137)$ \\
\hline Systolic blood pressure $<90$ & $2(0.9 \%)$ \\
\hline Diastolic blood pressure $(\mathrm{mmHg})$ & $72(64-80)$ \\
\hline Respiratory rate (breaths per minute) & $22(20-26)$ \\
\hline Respiratory rate $>24$ & $86(38.1 \%)$ \\
\hline Saturation of pulse oxygen & $97(95-99)$ \\
\hline Saturation of pulse oxygen $<90 \%$ & $14(6.2 \%)$ \\
\hline Temperature $\left({ }^{\circ} \mathrm{C}\right)$ & $36.7(36.4-37)$ \\
\hline$>37.3$ to $\leq 38$ & $21(9.3 \%)$ \\
\hline$>38$ & $24(10.6 \%)$ \\
\hline SOFA score $(n=192)$ & $4(2-8)$ \\
\hline ARDS & $161(71.2 \%)$ \\
\hline Mild ARDS & $35(15.5 \%)$ \\
\hline Moderate ARDS & $47(20.8 \%)$ \\
\hline Severe ARDS & $79(35.0 \%)$ \\
\hline Shock & $36(15.9 \%)$ \\
\hline Septic shock & $33(14.6 \%)$ \\
\hline Cardiogenic shock & $2(0.9 \%)$ \\
\hline Septic combined cardiogenic shock & $1(0.4 \%)$ \\
\hline Cardiac injury (hs-Tnl $>28 \mathrm{ng} / \mathrm{L}$ or $\mathrm{Tnl}>0.3 \mathrm{ng} / \mathrm{mL}$ ) & $61(27.0 \%)$ \\
\hline Arrhythmia & $21(9.3 \%)$ \\
\hline Atrial fibrillation & $18(8.0 \%)$ \\
\hline Supraventricular tachycardia & $2(0.9 \%)$ \\
\hline Ventricular tachycardia & $1(0.4 \%)$ \\
\hline Acute kidney injury by KDIGO criteria & $57(25.2 \%)$ \\
\hline Stage 1 & $23(10.2 \%)$ \\
\hline Stage 2 & $12(5.3 \%)$ \\
\hline Stage 3 & $22(9.7)$ \\
\hline Hospital-acquired bacterial or fungal infection & $49(21.7 \%)$ \\
\hline $\begin{array}{l}\text { Duration from the onset of symptom to the } \\
\text { current study, days }\end{array}$ & $33(27-37)$ \\
\hline Duration from ICU admission to the current study, days & $13(8-17.5)$ \\
\hline \multicolumn{2}{|l|}{ Infectious foci } \\
\hline Pulmonary & $45(19.9 \%)$ \\
\hline Pulmonary and bloodstream & $2(0.9 \%)$ \\
\hline Pulmonary and deep soft tissue & $1(0.4 \%)$ \\
\hline Urinary tract & $1(0.4 \%)$ \\
\hline Pneumothorax & $1(0.4 \%)$ \\
\hline Gastrointestinal hemorrhage & $7(3.1 \%)$ \\
\hline
\end{tabular}

Data are expressed as median (interquartile range) or count (\%). $N=226$ unless specified otherwise

COVID-19 coronavirus disease 2019, ICU intensive care unit, SOFA score, sequential organ failure estimation score, ARDS acute respiratory distress syndrome, KDIGO Kidney Disease: Improving Global Outcomes
The sequential organ failure assessment (SOFA) score was 4 (2-8). Organ function damages occurred in most of the patients: ARDS occurred in 161 (71.2\%) patients, including 35 (15.5\%) patients with mild ARDS, 47 (20.8\%) with moderate ARDS, and 79 (35.0\%) with severe ARDS. Shock occurred in 36 (15.9\%) patients, including septic shock in 34 (15.0\%) patients and cardiogenic shock in $3(1.3 \%)$ patients. Cardiac injury occurred in $61(27.0 \%)$ patients. AKI occurred in $57(25.2 \%)$ patients, including $23(10.2 \%)$, $12(5.3 \%)$, and $22(9.7 \%)$ patients with AKI of stage 1, stage 2 , and stage 3 , respectively.

Hospital-acquired infections were identified in 49 (21.7\%) patients. Of these patients, 1 (2.0\%) patient had urinary tract infection. The remaining 48 (98.0\%) patients were diagnosed with hospitalacquired pneumonia, including 2 patients and 1 patient having concomitant bloodstream infections and deep soft tissue infection, respectively. In 17 patients, the identifications of bacteria were pending. In 4 patients, carbapenem-resistant Enterobacteriaceae were entered into our web-based CRF. A total of 30 strains of bacteria were identified (Fig. 1) in the remaining 27 patients, including 3 patients with two kinds of bacteria in each of them. Among the 6 strains of Klebsiella pneumonia, 2 were resistant to carbapenems and 2 were positive for extendedspectrum $\beta$-lactamase.

\section{Laboratory tests (Table 3)}

Lymphocytopenia occurred in 160 (70.8\%) patients. Prolonged prothrombin time and activated partial thromboplastin time were observed from 30 (13.4\%) and $51(22.8 \%)$ patients, respectively. Elevated levels of glutamic pyruvic transaminase, glutamic oxalacetic transaminase, creatinine, and blood urea nitrogen were identified in 85 (37.6\%), 46 (20.4\%), 70 (31.0\%), and $140(61.9 \%)$ patients, respectively. Out of the 212 patients who had tests of D-dimer, elevated levels of D-dimer were identified in 189 (89.1\%) patients. For 162 patients who underwent tests on serum myoglobin, excessive myoglobin level was identified from 57 (35.2\%) patients, with the level higher than $1000 \mathrm{ng} /$ $\mathrm{mL}$ in $10(6.2 \%)$ patients.

\section{Managements (Table 4)}

Of all the patients, $85(37.6 \%)$ received invasive mechanical ventilation, with $14(6.2 \%)$ treated with extracorporeal membrane oxygenation (ECMO) at the same time and $20(8.8 \%)$ received noninvasive mechanical ventilation. Prone position ventilation was conducted in $22(9.7 \%)$ patients and continuous renal replacement therapy (CRRT) in 24 (10.6\%) patients. Spontaneous breathing test was conducted in 17 


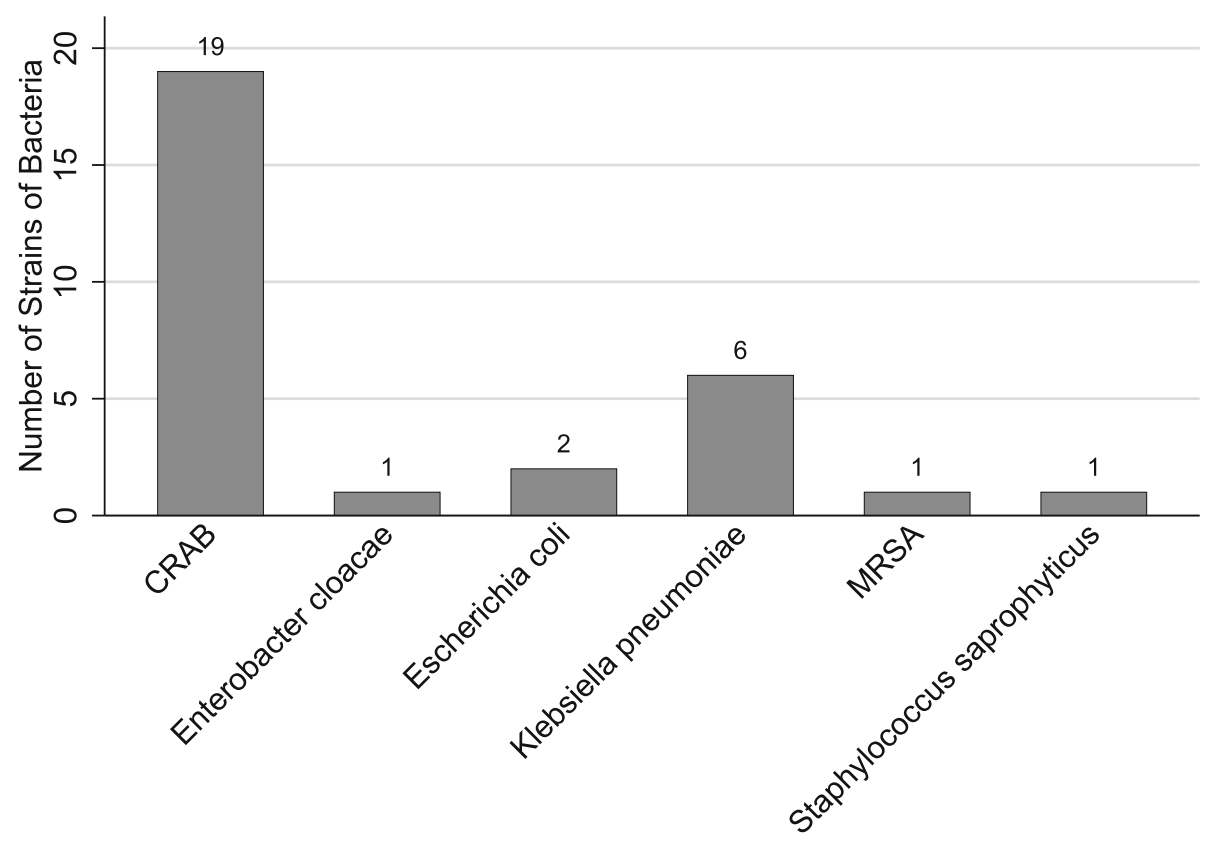

Fig. 1 Identified bacteria in patients with hospital-acquired pneumonia. CRAB, carbapenem-resistant Acinetobacter baumannii; MRSA, methicillinresistant Staphylococcus aureus

(7.5\%) patients, with $15(6.6 \%)$ failed and $2(0.9 \%)$ passed, and one $(0.4 \%)$ patient who passed the test was extubated.

Fifty-six (24.8\%) patients received chest radiological examinations including chest computed tomography and $\mathrm{X}$-ray; all the patients showed a bilateral lesion of the lungs (Fig. 2). Sixty-three (27.9\%) received an ultrasound examination, including $52(23.0 \%)$ chest or lung ultrasound examinations.

As for medications, 117 (51.8\%) patients received antivirus agents, 168 (74.3\%) received antimicrobial agents, $92(40.7 \%)$ received a subcutaneous injection of thymosin, $37(16.4 \%)$ patients received glucocorticoids intravenously, and $29(12.8 \%)$ patients received immunoglobulin.

\section{Outcomes}

At the end of the study, 204 (90.3\%) patients remained in the ICUs, 13 (5.7\%) were already discharged, and 9 (4.0\%) died during the observation period. By April 9, 2020 , among the 226 patients included, 87 (38.5\%) patients were deceased and $15(6.7 \%)$ were still in the hospital (Table 5).

\section{Discussion}

In this cross-sectional study on critically patients with COIVD-19, we found that ARDS occurred in 161 (71.2\%), septic shock occurred in 34 (15.0\%), AKI in $57(25.2 \%)$, and cardiac injury in $61(27 \%)$ of the 226 patients. Of all of them, 85 (37.6\%) were being treated with invasive mechanical ventilation, including $14(6.2 \%)$ on ECMO at the same time; $20(8.8 \%)$ treated with noninvasive mechanical ventilation; and $24(10.6 \%)$ treated with continuous renal replacement therapy. At the follow-up, 121 (53.5\%) were performed invasive mechanical ventilation and 87 (38.5\%) died.

To the extent of our knowledge, this study is by far the only prospective epidemiological study on critically ill patients with COVID-19. Based on the report published by the Chinese CDC, among all COVID-19 in China, 5\% were categorized critically ill, i.e., with respiratory failure, septic shock, and/or multiple organ dysfunction or failure [15]. On February 26, 2020, the number of accumulated patients with COVID-19 in China was 39,755 [16], which implies a sample of more than $10 \%$ of critically ill patients in China by the time have been presented in our study. We hope the information given here will shed light on the timely update of the critically ill patient care in an ICU in this global pandemic. We want to emphasize the major finding from this study that the intensive level of treatments needs to be given to a large portion of patients. In light of the exponential growth trend of the increased number of new COVID-19 cases, the critical care resources should be on the top list of the ICU warehouse against the pandemic disease. 
Table 3 Laboratory findings of 226 patients with COVID-19 in ICUs

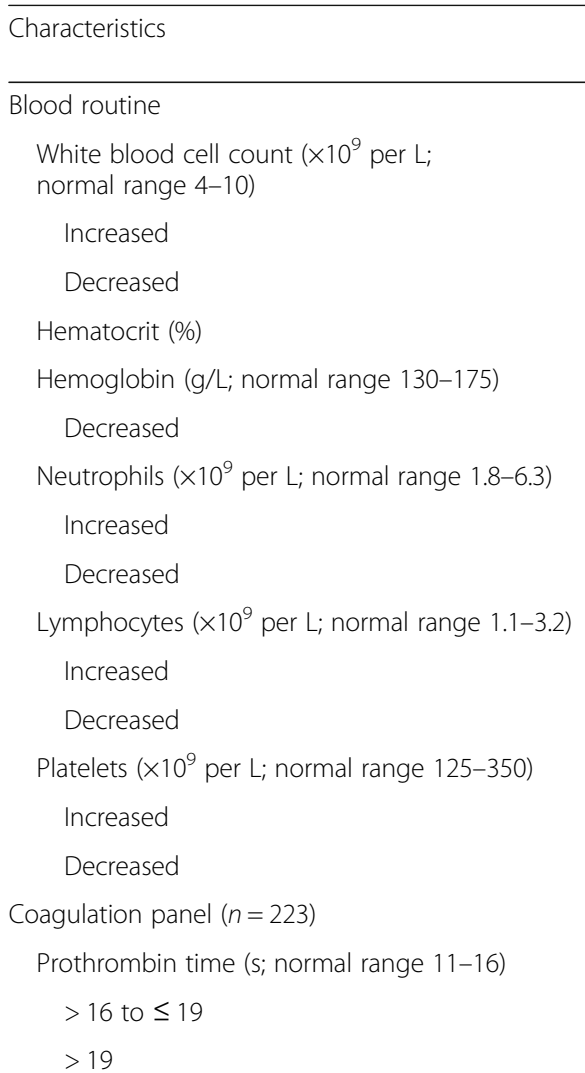

Activated partial thromboplastin time ( $s$; normal range $28-43.5$ )

$>43.5$ to $\leq 48.5$

$>48.5$

D-dimer $(n=212)(\mathrm{mg} / \mathrm{L} ;$ normal range $<0.5)$

$>0.5$ to $\leq 1$

$>1$

Hepatic function

Glutamic pyruvic transaminase

(U/L; normal range $<40)$

Increased

Glutamic oxalacetic transaminase

(U/L; normal range < 50v)

Increased

Total bilirubin concentration $(\mu \mathrm{mol} / \mathrm{L}$ normal range 3-22)

Increased

Albumin concentration ( $\mathrm{g} / \mathrm{L}$, normal range 35-50)

Decreased

Renal function

Serum creatinine concentration ( $\mu \mathrm{mol} / \mathrm{L}$, normal range 46-92)

Increased

Blood urea nitrogen (mmol/L, normal
All patients

$(n=226)$

$8.54(5.89-12.69)$

$95(42.0 \%)$

$16(7.1 \%)$

$31.1(26.3-35.7)$

$98(85-116)$

$220(97.3 \%)$

$7.28(4.24-10.94)$

$127(56.2 \%)$

$4(1.8 \%)$

$0.84(0.56-1.19)$

$1(0.4 \%)$

$160(70.8 \%)$

$181.5(115-258)$

$14(6.2 \%)$

$66(29.2 \%)$

$13(11.6-14.7)$

19 (8.5\%)

$11(4.9 \%)$

$32.3(26.1-42.1)$

$17(7.6 \%)$

$34(15.2 \%)$

$3(1.2-7.1)$

$20(9.4 \%)$

169 (79.7\%)

$31.2(19-57)$

$85(37.6 \%)$

$31.6(22-48)$

$46(20.4 \%)$

12.6 (8.6-19.1)

$42(18.6 \%)$

32.8 (29.4-36.9)

145 (64.2\%)

$64.2(49-111.6)$

$70(31.0 \%)$

7.34 (5.2-14.1)
Table 3 Laboratory findings of 226 patients with COVID-19 in ICUs (Continued)

\begin{tabular}{|c|c|}
\hline Characteristics & $\begin{array}{l}\text { All patients } \\
(n=226)\end{array}$ \\
\hline \multicolumn{2}{|l|}{ range $2.5-6.1$ ) } \\
\hline Increased & $140(61.9 \%)$ \\
\hline \multicolumn{2}{|l|}{ Serum electrolyte } \\
\hline Potassium (mmol/L, normal range 3.5-5.1) & $4.1(3.7-4.56)$ \\
\hline Sodium (mmol/L, normal range 135-145) & $140(137-144)$ \\
\hline \multicolumn{2}{|l|}{$\begin{array}{l}\text { Myoglobin plasma concentration }(n=162) \\
(\mathrm{ng} / \mathrm{mL} \text {, normal range }<150)\end{array}$} \\
\hline$<150$ & $105(64.8 \%)$ \\
\hline$\geq 150$ to $<1000$ & $47(29.0 \%)$ \\
\hline$\geq 1000$ & $10(6.2 \%)$ \\
\hline $\begin{array}{l}\text { Procalcitonin }(n=220)(\mathrm{ng} / \mathrm{mL} \text {, normal } \\
\text { range }<0.05)\end{array}$ & $0.19(0.05-1.4)$ \\
\hline$<0.05$ & $58(26.4 \%)$ \\
\hline $0.05-0.5$ & $80(36.4 \%)$ \\
\hline$>0.5$ & $82(37.3 \%)$ \\
\hline \multicolumn{2}{|c|}{ Ferritin concentration $(n=122)(\mu \mathrm{g} / \mathrm{L}$, normal range $<500)$} \\
\hline$<500$ & $31(25.4 \%)$ \\
\hline$\geq 500$ to $<1000$ & $33(27.1 \%)$ \\
\hline$\geq 1000$ to $<1500$ & $17(13.9 \%)$ \\
\hline$\geq 1500$ to $<2000$ & $10(8.2 \%)$ \\
\hline$\geq 2000$ & $31(25.4 \%)$ \\
\hline
\end{tabular}

Data are expressed as median (interquartile range) or count (\%). $N=226$ unless specified otherwise

COVID-19 coronavirus disease 2019, ICU intensive care unit

In our study, we found that the median age of all the patients included was 64 years, and $61.5 \%$ of the patients were male. Previous studies showed that the median age of critically ill patients with COVID-19 was $60-66$ years, and $67-70 \%$ of these patients were males $[8,9,17]$; ARDS tends to occur in male patients with advanced age [18, 19]. Another earlier publication reported that of the COVID-19 patients admitted to the ICU, 61.1\% were identified as ARDS, $41.7 \%$ received noninvasive ventilation, $47.2 \%$ received invasive ventilation, and $11.1 \%$ required ECMO [20]. These findings are in agreement or similar to the output of our study. However, from our data, 22 of 79 (36.7\%) patients with severe ARDS received prone position ventilation, which was much higher than the $8.7 \%$ reported in a cross-sectional survey of ARDS in mainland China in 2018 which did not involve COVID-19 patients [21]. This is a small sign that manifests the differentiation in treating patients in an ICU for a general situation versus the ongoing pandemic. 
Table 4 Managements

\begin{tabular}{|c|c|}
\hline Variables & All patients $(n=226)$ \\
\hline \multicolumn{2}{|l|}{ Respiratory support } \\
\hline None & $11(4.9 \%)$ \\
\hline Oxygen delivery by nasal cannula & $59(26.1 \%)$ \\
\hline Oxygen delivery by mask & $14(6.2 \%)$ \\
\hline High-flow nasal cannula (HFNC) & $37(16.4 \%)$ \\
\hline Noninvasive mechanical ventilation & $20(8.8 \%)$ \\
\hline Invasive mechanical ventilation & $85(37.6 \%)$ \\
\hline ECMO & $14(6.2 \%)$ \\
\hline Prone position & $22(9.7 \%)$ \\
\hline Continuous renal replacement therapy & $24(10.6 \%)$ \\
\hline Vasoactive drugs & $48(21.2 \%)$ \\
\hline Intravenous antihypertensive drugs & $14(6.2 \%)$ \\
\hline Central venous catheterization & $22(9.7 \%)$ \\
\hline Thoracic cavity closed drainage & $1(0.4 \%)$ \\
\hline Accidental removal of tracheal tube & $2(0.9 \%)$ \\
\hline Spontaneous breathing test & $17(7.5 \%)$ \\
\hline Spontaneous breathing test (failed) & $15(6.6 \%)$ \\
\hline Spontaneous breathing test (passed) & $2(0.9 \%)$ \\
\hline Removal of tracheal tube & $1(0.4 \%)$ \\
\hline Chest imaging examination & $56(24.8 \%)$ \\
\hline Ultrasound examination & $63(27.9 \%)$ \\
\hline Chest or lung ultrasound examination & $52(23.0 \%)$ \\
\hline Antivirus agent & $117(51.8 \%)$ \\
\hline Ribavirin & $35(15.49 \%)$ \\
\hline Ganciclovir & $6(2.65 \%)$ \\
\hline Interferon inhalation & $9(3.98 \%)$ \\
\hline Arbidol & $51(22.57 \%)$ \\
\hline Lopinavir-ritonavir & $12(5.31 \%)$ \\
\hline Neuaminidase inhibitors & $10(4.42 \%)$ \\
\hline Thymosin & $92(40.7 \%)$ \\
\hline Antimicrobial agents & $168(74.3 \%)$ \\
\hline Systemic glucocorticoids & $37(16.4 \%)$ \\
\hline Immunoglobulin & $29(12.8 \%)$ \\
\hline Blood transfusion & 19 (8.4\%) \\
\hline Red blood cell & $11(4.9 \%)$ \\
\hline Plasma & $9(4.0 \%)$ \\
\hline Blood platelet & $1(0.4 \%)$ \\
\hline Traditional Chinese herb & $59(26.1 \%)$ \\
\hline
\end{tabular}

Data are $n(\%)$ unless specified otherwise

We found that septic shock occurred in $15.0 \%$ of critically ill patients with COVID-19. Besides the hospital-acquired infection identified from 49 (21.7\%) patients, we postulate that SARS-CoV-2 could play an important role in the development of septic shock, based on the evidence that even 31 (24-36) days after the onset of symptoms, $70.8 \%$ still had lymphocytopenia. Whether there is viremia of SARS-CoV-2 causing septic shock is difficult to determine. But the bottom line is that lymphocytopenia was associated with an increased risk of acquired infection in ICU [22]. And lymphocytopenia was proved to be associated with the probability of 28-day septic shock and 28-day mortality [23].

The rate of AKI in critically ill patients with COVID-19 was high. The pathogenesis of AKI has not been fully understood yet, but it may be associated with ACE2, the cell entry receptor of the SARSCoV-2. It has been identified to be exclusively expressed not only in the respiratory organs, but also in other organs, for example, the kidney, which may facilitate the direct invasion and damage [24]. CRRT was used in $10.6 \%$ of our patients during the study, compared with $5 \%$ of critically ill patients during the SARS epidemic in Canada [25]. We are facing a worse situation in using CRRT now compared with the SARS outbreak.

One unexpected finding was that 57 (35.2\%) critically ill patients with COVID-19 were with increased levels of myoglobin. One third of the overall COVID-19 patients were experiencing myalgia [20]. A possible explanation is that the SARS-CoV-2 might damage the muscle system. Whether the damage leads to muscle weakness and thereby causes failure of spontaneous breathing trial needs further evaluation.

Physicians treating patients with COVID-19 were under personal protective equipment, which made them impossible to perform an auscultation. Lung ultrasound was an effective technique to replace auscultation and assess the etiologies of lung abnormalities and their severity level [26]. A total of $52(23.0 \%)$ patients received chest or lung ultrasound examinations during the period. At the same time, $56(24.8 \%)$ patients received chest imaging examinations, which might consume more medical resources than ultrasound, especially in the isolation wards. Training more physicians capable of doing chest or lung ultrasound might reduce the dependence on chest imaging examinations.

Previous study reported different mortality rates in critically ill patients, from $16.7 \%$ [20] to $26 \%$ [27], $61.5 \%$ [11], and $67 \%$ [28]. In our study, only $6.7 \%$ of the patients were still hospitalized in the general wards or ICUs, compared with 58.3\% hospitalized [20] and 58\% in ICUs [27], and $23.1 \%$ hospitalized [11] and $24 \%$ in ICUs [28] in other studies, respectively. The mortality rates get higher if the follow-up time prolongs. However, the criteria for ICU admission were different among the studies, which was another reason for the different mortality rates. 


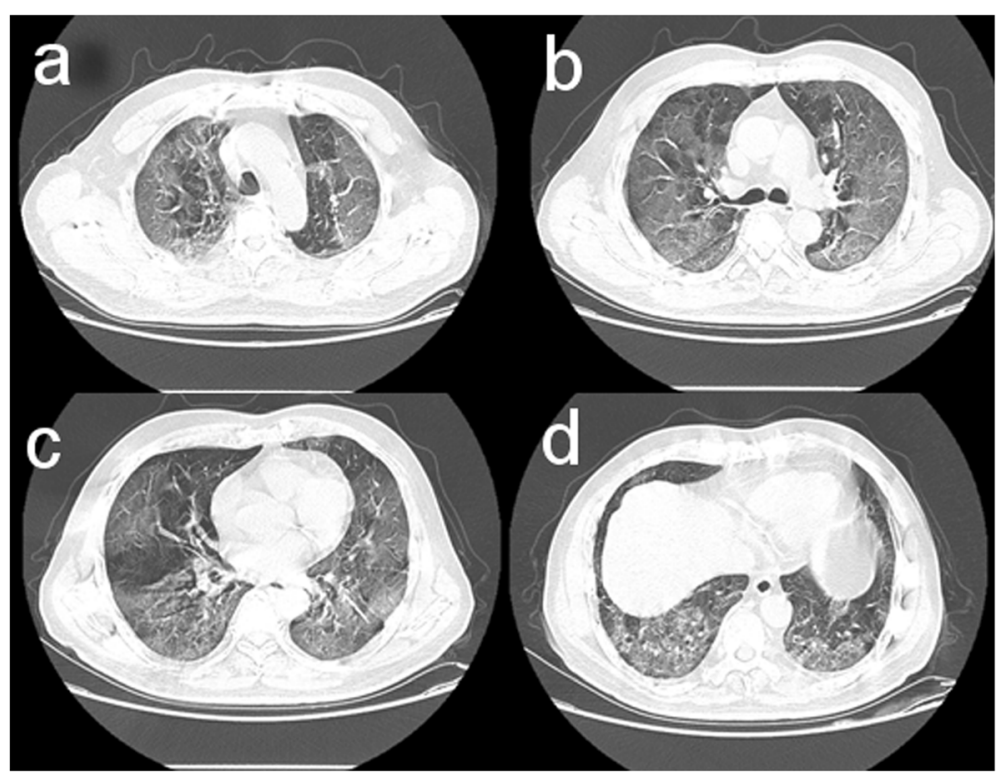

Fig. 2 Chest computed tomographic imaging of the lungs performed on February 26, 2020, showed ground-glass opacity in the bilateral lungs on day 10 after symptom onset

Our study has some limitations. First, our study was conducted only in Wuhan, China. But on February 26, 2020, 32,392 in 39,755 (81.5\%) patients being treated were in Wuhan [16]. We believe the rate of critically ill patients being treated in Wuhan was higher than $81.5 \%$, which meant that the findings from this study could probably be generalized. Second, the selection of ICUs was not random. However, all the ICUs were selected from the hospital designated for patients with COVID-19 only, and all the ICUs were closed adult units, staffed by qualified fulltime intensive care physicians and nurses for $24 \mathrm{~h}$. Third, some important data, for example, arterial blood gas analysis, were not available in some patients. That was because this study was an observational study, and we intended to intervene in the routine practices of different ICUs as less as possible. Forth, the appointed physicians most likely were not the treating physicians for all the patients in their ICUs. All the directors appointed two experienced physicians for the study, who tried to eliminate the bias by clearing uncertainties with the treating physicians.

\section{Conclusion}

Critically ill patients with COVID-19 are associated with considerable rates of severe complications and need treatments of high intensity. COVID-19 poses great strains on critical care resources in hospitals.

Table 5 Outcomes of 226 patients with COVID-19 by April 9, 2020

\begin{tabular}{|c|c|c|c|c|c|c|c|}
\hline \multirow[t]{2}{*}{ Outcome } & \multicolumn{6}{|c|}{ Age groups (years) } & \multirow{2}{*}{$\begin{array}{l}\text { All patients } \\
(n=226)\end{array}$} \\
\hline & $30-40(n=7)$ & $41-50(n=19)$ & $51-60(n=51)$ & $61-70(n=97)$ & $71-80(n=35)$ & $81-90(n=17)$ & \\
\hline Still hospitalized & $0(0.0 \%)$ & $2(10.5 \%)$ & $4(7.8 \%)$ & $8(8.3 \%)$ & $0(0.0 \%)$ & $1(5.9 \%)$ & $15(6.7 \%)$ \\
\hline Discharged & $7(100.0 \%)$ & $8(42.1 \%)$ & $31(60.8 \%)$ & $45(46.4 \%)$ & $23(65.7 \%)$ & $10(58.8 \%)$ & $124(54.9 \%)$ \\
\hline Died & $0(0.0 \%)$ & $9(47.4 \%)$ & $16(31.4 \%)$ & $44(45.4 \%)$ & $12(34.3 \%)$ & $6(35.3 \%)$ & 87 (38.5\%) \\
\hline Died with DNI & $0(0.0 \%)$ & $0(0.0 \%)$ & $1(2.0 \%)$ & $3(3.1 \%)$ & $0(0.0 \%)$ & $3(17.6 \%)$ & $7(3.1 \%)$ \\
\hline Patients received IMV & $4(57.1 \%)$ & 15 (78.9\%) & $25(49.0 \%)$ & $55(56.7 \%)$ & $18(51.4 \%)$ & $4(23.5 \%)$ & $121(53.5 \%)$ \\
\hline Died ever receiving IMV & $0(0.0 \%)$ & $9(47.4 \%)$ & 15 (29.4\%) & $40(41.2 \%)$ & $12(34.2 \%)$ & $3(17.6 \%)$ & 79 (35.0\%) \\
\hline Received NIV before IMV & $3(42.9 \%)$ & $6(31.6 \%)$ & $11(21.6 \%)$ & $29(29.9 \%)$ & $12(34.3 \%)$ & $1(5.9 \%)$ & $62(27.4 \%)$ \\
\hline
\end{tabular}

Data are expressed as count (\%)

COVID-19 coronavirus disease 2019, DNI do not intubate, IMV invasive mechanical ventilation, NIV noninvasive ventilation 


\section{Abbreviations}

COVID-19: Coronavirus disease 2019; ICU: Intensive care unit; ARDS: Acute respiratory distress syndrome; ECMO: Extracorporeal membrane oxygenation; AKI: Acute kidney injury; KDIGO: Kidney Disease: Improving Global Outcomes; SOFA: Sequential organ failure assessment; CRRT: Continuous renal replacement therapy; CDC: Centers for disease control

\section{Acknowledgements}

We thank all the patients and their families involved in the study.

\section{Authors' contributions}

YY, DX, SF, JZ, XY, LX, JX, YW, CH, YO, LY, MF, HW, JM, WZ, SH, QH, DD, MH, $G Z, W X, J G, J i X, H Y$, and $B Z$ collected the epidemiological and clinical data. $Y Y, X Y$, and $Y W$ summarized all the data. $Y Y, D X, S F, J Z, X Y$, and $L X$ drafted the manuscript. ZY, DC, SY, and YS revised the final manuscript. The author(s) read and approved the final manuscript.

\section{Funding}

This study had no external funding source.

\section{Availability of data and materials}

After publication, the date will be made available to others on reasonable requests to the corresponding author. A proposal with a detailed description of the study objectives and statistical analysis plan will be needed for the evaluation of the reasonability of requests. Additional materials might also be required during the process of evaluation. Deidentified participant data will be provided after the approval of the corresponding author and Wuhan Jinyintan Hospital.

\section{Ethics approval and consent to participate}

This study was approved by the Ethics Committee of Jinyintan Hospital (KY2020-25.01), and written informed consent was waived.

\section{Consent for publication}

Written informed consent for publication was obtained from all authors.

\section{Competing interests}

All the authors state that there are no conflicts of interest related to this study.

\section{Author details}

'Department of Critical Care Medicine, Union Hospital, Tongji Medical College, Huazhong University of Science and Technology, Wuhan, China. ${ }^{2}$ Department of Intensive Care Unit, Wuhan Third Hospital, Wuhan, China. ${ }^{3}$ Department of Critical Care Medicine, Wuhan Hospital of Traditional Chinese Medicine, Wuhan, China. ${ }^{4}$ Department of Critical Care Medicine, Wuhan Wuchang Hospital, Wuhan, China. ${ }^{5}$ Jinyintan Hospital, Wuhan, China. ${ }^{6}$ Department of Emergency Internal Medicine, Tongji Hospital, Tongji Medical College, Huazhong University of Science and Technology, Wuhan, China. ${ }^{7}$ Intensive Care Unit, Xiehe Wuhan Red Cross Hospital, Wuhan, China. ${ }^{8}$ Department of Intensive Care Unit, Liyuan Hospital Affiliated to Tongji Medical College of Huazhong University of Science and Technology, Wuhan, China. ${ }^{9}$ Intensive Care Unit, Tianyou Hospital Affiliated to Wuhan University of Science and Technology, Wuhan, China. ${ }^{10}$ Intensive Care Unit, Fifth Hospital in Wuhan, Wuhan, China. ${ }^{11}$ Intensive Care Unit, The First People's Hospital of Jiangxia District, Wuhan, China. ${ }^{12}$ Department of Critical Care Medicine, Wuhan Pulmonary Hospital, Wuhan, China. ${ }^{13}$ Department of Critical Care Medicine, The Affiliated Hospital of Jianghan University, Wuhan, China. ${ }^{14}$ Department of Critical Care Medicine, The Central Hospital of Wuhan, Tongji Medical College, Huazhong University of Science and Technology, Wuhan, China. ${ }^{15}$ Intensive Care Unit, Union Jiangbei Hospital, Huazhong University of Science and Technology, Wuhan, China. ${ }^{16}$ Intensive Care Unit, Dongxi Lake District People's Hospital, Wuhan, China.

${ }^{17}$ Department of Intensive Care Unit, The Second People's Hospital of Three Gorges University, Yichang, China. ${ }^{18}$ Department of Critical Care Medicine, Renmin Hospital of Wuhan University, Wuhan, China. ${ }^{19}$ Department of Critical Care Medicine, Ruijin Hospital, Shanghai Jiao Tong University School of Medicine, Shanghai, China.
Received: 27 March 2020 Accepted: 30 April 2020

Published online: 14 May 2020

\section{References}

1. Lu H, Stratton CW, Tang YW. Outbreak of pneumonia of unknown etiology in Wuhan, China: the mystery and the miracle. J Med Virol. 2020. https://doi. org/10.1002/jmv.25678.

2. Hui DS, Azhar El, Madani TA, Ntoumi F, Kock R, Dar O, Ippolito G, TD MH, Memish ZA, Drosten C, Zumla A, Petersen E. The continuing 2019-nCoV epidemic threat of novel coronaviruses to global health - the latest 2019 novel coronavirus outbreak in Wuhan, China. Int J Infect Dis. 2020;91:264-6. https://doi.org/10.1016/j.jijid.2020.01.009.

3. Paules $\mathrm{Cl}$, Marston HD, Fauci AS. Coronavirus infections-more than just the common cold. JAMA. 2020. https://doi.org/10.1001/jama.2020.0757.

4. WHO. Situation report-55. https://www.who.int/docs/default-source/ coronaviruse/situation-reports/20200315-sitrep-55-covid-19.pdf?sfvrsn=33 daa5cb_6. Accessed 12 Apr 2020

5. National Health Commission of the People's Republic of China. March 16: daily briefing on novel coronavirus cases in China. (2020). http://en.nhc.gov. cn/2020-03/16/c_77760.htm.

6. WHO: Shortage of personal protective equipment endangering health workers worldwide. https://www.who.int/news-room/detail/03-03-2020shortage-of-personal-protective-equipment-endangering-health-workersworldwide. Accessed 12 Apr 2020.

7. Ji Y, Ma Z, Peppelenbosch MP, Pan Q. Potential association between COVID19 mortality and health-care resource availability. Lancet Glob Health. 2020. https://doi.org/10.1016/S2214-109X(20)30068-1.

8. Huang C, Wang Y, Li X, Ren L, Zhao J, Hu Y, Zhang L, Fan G, Xu J, Gu X, Cheng Z, Yu T, Xia J, Wei Y, Wu W, Xie X, Yin W, Li H, Liu M, Xiao Y, Gao H, Guo L, Xie J, Wang G, Jiang R, Gao Z, Jin Q, Wang J, Cao B. Clinical features of patients infected with 2019 novel coronavirus in Wuhan, China. Lancet. 2020;395(10223):497-506. https://doi.org/10.1016/S0140-6736(20)30183-5.

9. Chen N, Zhou M, Dong X, Qu J, Gong F, Han Y, Qiu Y, Wang J, Liu Y, Wei Y, Xia J, Y U T, Zhang X, Zhang L. Epidemiological and clinical characteristics of 99 cases of 2019 novel coronavirus pneumonia in Wuhan, China: a descriptive study. Lancet. 2020;395(10223):507-13. https://doi.org/10.1016/ S0140-6736(20)30211-7.

10. Zhu N, Zhang D, Wang W, Li X, Yang B, Song J, Zhao X, Huang B, Shi W, Lu R, Niu P, Zhan F, Ma X, Wang D, Xu W, Wu G, Gao GF, Tan W, China Novel Coronavirus I, Research T. A novel coronavirus from patients with pneumonia in China, 2019. N Engl J Med. 2020;382(8):727-33. https://doi. org/10.1056/NEJMoa2001017.

11. Yang X, Yu Y, Xu J, Shu H, Xia J, Liu H, Wu Y, Zhang L, Yu Z, Fang M, Yu T, Wang Y, Pan S, Zou X, Yuan S, Shang Y. Clinical course and outcomes of critically ill patients with SARS-CoV-2 pneumonia in Wuhan, China: a singlecentered, retrospective, observational study. Lancet Respir Med. 2020. https://doi.org/10.1016/S2213-2600(20)30079-5.

12. Force ADT, Ranieri VM, Rubenfeld GD, Thompson BT, Ferguson ND, Caldwell E, Fan E, Camporota L, Slutsky AS. Acute respiratory distress syndrome: the Berlin definition. JAMA. 2012;307(23):2526-33. https://doi.org/10.1001/jama. 2012.5669.

13. Singer M, Deutschman CS, Seymour CW, Shankar-Hari M, Annane D, Bauer M, Bellomo R, Bernard GR, Chiche JD, Coopersmith CM, Hotchkiss RS, Levy MM, Marshall JC, Martin GS, Opal SM, Rubenfeld GD, van der Poll T, Vincent $J$, Angus DC. The Third International Consensus Definitions for Sepsis and Septic Shock (Sepsis-3). JAMA. 2016;315(8):801-10. https://doi.org/10.1001/ jama.2016.0287.

14. Khwaja A. KDIGO clinical practice guidelines for acute kidney injury. Nephron Clin Pract. 2012;120(4):c179-84. https://doi.org/10.1159/000339789.

15. Wu Z, McGoogan JM. Characteristics of and important lessons from the coronavirus disease 2019 (COVID-19) outbreak in China: summary of a report of 72314 cases from the Chinese Center for Disease Control and Prevention. JAMA. 2020. https://doi.org/10.1001/jama.2020.2648.

16. National Health Commission of the People's Republic of China. Feb 27: daily briefing on novel coronavirus cases in China. http://en.nhc.gov.cn/2020-02/2 7/c_76975.htm. Accessed 12 Apr 2020.

17. Guan WJ, Ni ZY, Hu Y, Liang WH, Ou CQ, He JX, Liu L, Shan H, Lei CL, Hui DSC, Du B, Li LJ, Zeng G, Yuen KY, Chen RC, Tang CL, Wang T, Chen PY, Xiang J, Li SY, Wang JL, Liang ZJ, Peng YX, Wei L, Liu Y, Hu YH, Peng P, Wang JM, Liu JY, Chen Z, Li G, Zheng ZJ, Qiu SQ, Luo J, Ye CJ, Zhu SY, Zhong NS, China Medical Treatment Expert Group for C. Clinical 
characteristics of coronavirus disease 2019 in China. N Engl J Med. 2020. https://doi.org/10.1056/NEJMoa2002032.

18. Laffey JG, Madotto F, Bellani G, Pham T, Fan E, Brochard L, Amin P, Arabi Y, Bajwa EK, Bruhn A, Cerny V, Clarkson K, Heunks L, Kurahashi K, Laake JH, Lorente JA, McNamee L, Nin N, Palo JE, Piquilloud L, Qiu H, Jimenez JIS, Esteban A, McAuley DF, van Haren F, Ranieri M, Rubenfeld G, Wrigge H, Slutsky AS, Pesenti A, Investigators LS, Group ET. Geo-economic variations in epidemiology, patterns of care, and outcomes in patients with acute respiratory distress syndrome: insights from the LUNG SAFE prospective cohort study. Lancet Respir Med. 2017;5(8):627-38. https://doi.org/10.1016/ S2213-2600(17)30213-8.

19. McNicholas BA, Rooney GM, Laffey JG. Lessons to learn from epidemiologic studies in ARDS. Curr Opin Crit Care. 2018;24(1):41-8. https://doi.org/10. 1097/MCC.0000000000000473.

20. Wang D, Hu B, Hu C, Zhu F, Liu X, Zhang J, Wang B, Xiang H, Cheng Z, Xiong Y, Zhao Y, Li Y, Wang X, Peng Z. Clinical characteristics of 138 hospitalized patients with 2019 novel coronavirus-infected pneumonia in Wuhan, China. JAMA. 2020. https://doi.org/10.1001/jama.2020.1585.

21. Liu L, Yang Y, Gao Z, Li M, Mu X, Ma X, Li G, Sun W, Wang X, Gu Q, Zheng R, Zhao H, Ao D, Yu W, Wang Y, Chen K, Yan J, Li J, Cai G, Wang Y, Wang H, Kang Y, Slutsky AS, Liu S, Xie J, Qiu H. Practice of diagnosis and management of acute respiratory distress syndrome in mainland China: a cross-sectional study. J Thorac Dis. 2018;10(9):5394-404. https://doi.org/10. 21037/jtd.2018.08.137.

22. Adrie C, Lugosi M, Sonneville R, Souweine B, Ruckly S, Cartier JC, GarrousteOrgeas M, Schwebel C, Timsit JF, Group OS. Persistent lymphopenia is a risk factor for ICU-acquired infections and for death in ICU patients with sustained hypotension at admission. Ann Intensive Care. 2017;7(1):30. https://doi.org/10.1186/s13613-017-0242-0.

23. Sheikh Motahar Vahedi H, Bagheri A, Jahanshir A, Seyedhosseini J, Vahidi E. Association of lymphopenia with short term outcomes of sepsis patients; a brief report. Arch Acad Emerg Med. 2019;7(1):e14.

24. Li Z, Wu M, Guo J, Yao J, Liao X, Song S, Han M, Li J, Duan G, Zhou Y, Wu X, Zhou Z, Wang T, Hu M, Chen X, Fu Y, Lei C, Dong H, Zhou Y, Jia H, Chen X, Yan J (2020) Caution on kidney dysfunctions of 2019-nCoV patients. medRxiv:2020.2002.2008.20021212. doi:https://doi.org/10.1101/2020.02.08. 20021212.

25. Fowler RA, Lapinsky SE, Hallett D, Detsky AS, Sibbald WJ, Slutsky AS, Stewart TE, Toronto SCCG. Critically ill patients with severe acute respiratory syndrome. JAMA. 2003;290(3):367-73. https://doi.org/10.1001/jama.290.3.367.

26. See KC, Ong V, Tan YL, Sahagun J, Taculod J. Chest radiography versus lung ultrasound for identification of acute respiratory distress syndrome: a retrospective observational study. Crit Care. 2018;22(1):203. https://doi.org/ 10.1186/s13054-018-2105-y.

27. Grasselli G, Zangrillo A, Zanella A, Antonelli M, Cabrini L, Castelli A, Cereda D, Coluccello A, Foti G, Fumagalli R, lotti G, Latronico N, Lorini L, Merler S, Natalini G, Piatti A, Ranieri MV, Scandroglio AM, Storti E, Cecconi M, Pesenti A, Network C-LI. Baseline characteristics and outcomes of 1591 patients infected with SARS-CoV-2 admitted to ICUs of the Lombardy region, Italy. JAMA. 2020. https://doi.org/10.1001/jama.2020.5394.

28. Arentz M, Yim E, Klaff L, Lokhandwala S, Riedo FX, Chong M, Lee M. Characteristics and outcomes of 21 critically ill patients with COVID-19 in Washington state. JAMA. 2020. https://doi.org/10.1001/jama.2020.4326.

\section{Publisher's Note}

Springer Nature remains neutral with regard to jurisdictional claims in published maps and institutional affiliations.

Ready to submit your research? Choose BMC and benefit from:
- fast, convenient online submission
- thorough peer review by experienced researchers in your field
- rapid publication on acceptance
- support for research data, including large and complex data types
- gold Open Access which fosters wider collaboration and increased citations
- maximum visibility for your research: over 100M website views per year
At BMC, research is always in progress.
Learn more biomedcentral.com/submissions

